\title{
Corrigendum: Multiphoton imaging reveals a new leukocyte recruitment paradigm in the glomerulus
}

Sapna Devi, Anqi Li, Clare L V Westhorpe, Camden Y Lo, Latasha D Abeynaike, Sarah L Snelgrove, Pam Hall, Joshua D Ooi, Christopher G Sobey, A Richard Kitching \& Michael J Hickey

Nat. Med. 19, 107-112 (2013); published online 16 December 2012; corrected after print 12 August 2015

In the published article, in the Online Methods section, it is stated that the dose of DHE used is $20 \mathrm{mg} / \mathrm{kg}$, when in fact DHE was administered at $2 \mathrm{mg} / \mathrm{kg}$. The error has been corrected in the HTML and PDF versions of the article.

\section{Corrigendum: PAR1 signaling regulates the retention and recruitment of EPCR-expressing bone marrow hematopoietic stem cells}

Shiri Gur-Cohen, Tomer Itkin, Sagarika Chakrabarty, Claudine Graf, Orit Kollet, Aya Ludin, Karin Golan, Alexander Kalinkovich, Guy Ledergor, Eitan Wong, Elisabeth Niemeyer, Ziv Porat, Ayelet Erez, Irit Sagi, Charles T Esmon, Wolfram Ruf \& Tsvee Lapidot Nat. Med. 21, 1307-1317 (2015); published online 12 October 2015; corrected after print 18 November 2015

In the version of this article initially published, the first author's name was incorrect. The error has been corrected in the HTML and PDF versions of the article.

\section{Corrigendum: Myeloid-derived growth factor (C19orf10) mediates cardiac repair following myocardial infarction}

\footnotetext{
Mortimer Korf-Klingebiel, Marc R Reboll, Stefanie Klede, Torben Brod, Andreas Pich, Felix Polten, L Christian Napp, Johann Bauersachs, Arnold Ganser, Eva Brinkmann, Ines Reimann, Tibor Kempf, Hans W Niessen, Jacques Mizrahi, Hans-Joachim Schönfeld, Antonio Iglesias, Maria Bobadilla, Yong Wang \& Kai C Wollert

Nat. Med. 21, 140-149 (2015); published online 12 January 2015; corrected after print 19 November 2015

In the version of this article initially published, the article number in reference 13 is incorrectly stated as '100ra190' and should be ' $100 \mathrm{ra} 90$ '. The error has been corrected in the HTML and PDF versions of the article.
}

\section{Corrigendum: A SARS-like cluster of circulating bat coronaviruses shows potential for human emergence}

Vineet D Menachery, Boyd L Yount Jr, Kari Debbink, Sudhakar Agnihothram, Lisa E Gralinski, Jessica A Plante, Rachel L Graham, Trevor Scobey, Xing-Yi Ge, Eric F Donaldson, Scott H Randell, Antonio Lanzavecchia, Wayne A Marasco, Zhengli-Li Shi \& Ralph S Baric Nat. Med.; doi:10.1038/nm.3985; corrected 20 November 2015

In the version of this article initially published online, the authors omitted to acknowledge a funding source, USAID-EPT-PREDICT funding from EcoHealth Alliance, to Z.-L.S. The error has been corrected for the print, PDF and HTML versions of this article.

\section{Corrigendum: Long-term glycemic control using polymer-encapsulated human stem cell-derived beta cells in immune-competent mice}

Arturo J Vegas, Omid Veiseh, Mads Gürtler, Jeffrey R Millman, Felicia W Pagliuca, Andrew R Bader, Joshua C Doloff, Jie Li, Michael Chen, Karsten Olejnik, Hok Hei Tam, Siddharth Jhunjhunwala, Erin Langan, Stephanie Aresta-Dasilva, Srujan Gandham, James J McGarrigle, Matthew A Bochenek, Jennifer Hollister-Lock, Jose Oberholzer, Dale L Greiner, Gordon C Weir, Douglas A Melton, Robert Langer \& Daniel G Anderson

Nat. Med.; doi:10.1038/nm.4030; corrected online 18 February 2016

In the version of this article initially published online, the authors omitted acknowledgment recognizing the histology core of the Harvard Stem Cell Institute and several individuals for their assistance. The error has been corrected for the print, PDF and HTML versions of this article. 